\title{
A Margem de um Estudo
}

FERNANDO FIGUEIREDO DE ABRANCHES

Advogado

SUMARIO: 1 - A competência do Poder Judiciário para o julgamento dos litígios decorrentes de acidentes do trabalho, na Constituição de 1969. 2 - A orientaçäo do SUPREMO TRIBUNAL FEDERAL a respeito, sem alterar as Súmulas n?s 235 a 501, ñ̋o percebendo o novo conceito de seguro social, definido naquela Constituiçẽo (art. 165, III), no qual está incluido o de contra acidentes do trabalho, considerou letra morta a disposição constitucional. 3 - Conseqüências: A anomalia que se criou, sem um Tribunal a uniformizar a jurisprudência, desde que o S.T.F. abdicou de sua competência e a excluiu do Tribunal Federal de Recursos arranhou o sistema federativo, permitindo a existência de um Direito do Trabalho sobre o tema, em cada Estado da Federação e no Distrito Federal, divergindo os Tribunais entre eles e entre uns e ouiros, fato inusitado e que deixou perplexos os juristas. 4 - Agrava-se a anomalia quando, atônito, - INPS, monopolizador deste seguro, por força da Constituição, vê o seu patrimônio esvair-se, com decisões afrontadoras à Lei de infortunística, sem melos ao seu alcance para evitar a circunstância. 5 - Os Tribunais de Justiça dos Estados deveriam tentar corrigir, com a construção de teses, os efeitos da jurisprudência predominante na Suprema-Corte, o que, por uma de suas Turmas, o do Distrito Federal, com indispensável mérito, tenta fazer, com resultados benéficos, contudo, sem profundidade porque a outra Turma e os Tribunais de Justiça dos Estados poderiam entender que os seus julgados seriam mais correlos.

1. Este trabalho é complemento de estudo a que se deu o título de COMPETENCIA DOS JUIZES FEDERAIS PARA O JULGAMENTO DAS AÇÕES DE ACIDENTE DO TRABALHO NA CONSTITUIÇÃO DE 1969.

E induvidoso que as teses desenvolvidas não mereceram o beneplácito do Egrégio Supremo Tribunal Federal, inobstante alguns Tribunais de Justiça dos Estados, inclusive, o do Distri- to Federal, as tivessem adotado, talvez, sob outros argumentos.

Entretanto, nem por isto, a matéria deixou de ser palpitante.

2. Procurou-se mostrar que, com o advento da Constituição de 1969, o seguro contra acidentes do trabalho sofreu substancial transformação, com a redação de seu art. 165 , inciso III, e, rompendo, a tradição da Carta Política de 1967 e da Constituição de 
1946, inovou o principio do seguro social, ao mesmo tempo em que instituiu um novo sistema.

Enquanto na vigência das Constituições anteriores, o seguro contra acidentes do trabalho não se incluia na definição do seguro social, na atual Carta Política passou a ter essa conceituação.

Assim, seguro social, o que não ocorria antes, constituiu-se em previdência social nos casos de doenças, velhice, invalidez e morte, seguro-desemprego, contra acidentes do trabatho e proteção da maternidade, mediante a contribuição da União, do empregador $\theta$ do empregado.

Em razão da nova conceituação do seguro social, as ações de acidente do trabalho seriam da competência dos juizes federais, com recurso para o Tribunal Federal de Recursos, na ordenada interpretação dos arts. 165, III, 142 $\S 2$, 125 , inciso $\mathrm{I}$, e seu $\S 3$ ?, 110 , e 104, da Constituição de 1969. 1

"Ora, continuava o raciocínio, "o seguro contra acidentes do trabalho, hoje, seguro social, é, sem dúvida, benefício de natureza pecuniária. Os benefícios dele emanados são sempre uma prestação em dinheiro e o seu pagamento é feito pela autarquia previdenciária e em qualquer ação dessa natureza ela será parte". 2

3. Esperava-se que, por isto, as SÚMULAS nọ 235 e 501, do Pretório Excelso fossem alteradas, uma vez que os arestos que the serviram de base foram inspirados nos preceitos das Constituiçöes anteriores.

\section{SÚMULA No 235 (DUZENTOS E} TRINTA E CINCO)

É competente para a ação de acidente do trabalho a Justiça Cível comum, inclusive, em segunda instância, ainda que seja parte autarquia seguradora". 3

\section{REFERENCIA}

C.F. Art. 201; L.A.T., Art. 100;

L. 2.285, de 9-8-54; DL 9.863, de 30-8-46, Art. 12.

ERE 44.590, de 17-4-61,

LTr. 26/283

ERE $n \div 46.008$, de 2-5-61. RE n? 44.824, de 6-6-61."4

Não será necessário grande esforço de indagação para constatar que as referências, sem exceção, dizem respeito a ações de acidente do trabaIho, nas quais o seguro respectivo não se integrara no conceito de seguro social, nascido com a Carta Política vigente.

Todas as hipóteses referiam-se a ações em que alguma das autarquias previdenciárias, antes da estatização do seguro contra acidentes do trabaIho, tivessem feito esse contrato em concorrência com as empresas seguradoras particulares.

Entretanto, Data Venia, e lamentavelmente, a jurisprudência predominante e consubstanciada nas Súmulas, ao contrário do que era de supor-se,

1 ABRANCHES, Fernando Figueiredo do Competência dos Juizes Federais para o julgamento das açőes de acidentes do trabalho na Constituiçăo de 1969 (Estudos, impresso - pág. 18).

2 Idem, págs. 10, 13, 15 e 19.

3 Idem, pág. 15.

4 NORONHA, Jardel e MARTINS, Odaléa - REFERENCIAS DA SÚMULA DO SUPREMO TRIBUNAL FEDERAL, Vol. 12, pág. 92, Serviço Gráfico - Senado Federal. 
manteve-se sem modificação e, mais, reforçada com julgados à vista dos dispositivos da nova Carta Política.

Para comprovação da afirmativa e melhor elucidação da matéria transcrever-se-á o Acórdão do Supremo Tribunal Federal, de 14-5-70, no Conflito de Jurisdição n: 5.345 , em sessão $\mathrm{Ple}$ na.

Conflito de jurisdição $n^{\circ} 5.345-$ Tribunal Pleno suscitante: Tribunal Federal de Recursos suscitado: Tribunal de Alçada do Est. da Guanabara. Ementa: Conf́lito de jurisdição - 0 Tribunal de Alçada é competente para apreciar, em segunda instância, as ações de acidente do trabalho, ainda que acionada seja autarquia federal ou a própria União. Conflito conhecido e julgado procedente.

\section{Acórdão}

Vistos, relatados e discutidos estes autos, acordam os Ministros do Supremo Tribunal Federal, em sessão plena, por unanimidade do votos, julgar competente o Tribunal de Alçada da Guanabara, na conformidade da ata do julgamento e das notas taquigráficas anexas.

Brasilia, D.F., 14 de Maio de 1970 - Oswaldo Trigueiro, Presidente Amaral Santos, Relator

\section{Relatório}

O SR. MINISTRO AMARAL SANTOS - O Tribunal de Alçada do Estado da Guanabara, em ação de acidente do trabalho, em que há interesse de autarquia Federal, declinou de sua competência, através do Acórdão de fls. 80 , e determinou a remessa dos autos ao Tribunal Federal de Recursos.
Em decisão de fls. 91, o Tribunal Federal de Recursos também se considerou incompetente, por entender que a competência para ações de acidente do trabalho é da justiça estadual ou local, e, em consequência, suscitou o presente conflito negativo de jurisdição.

Opina a douta Procuradoria da República nestes termos (fls. 99):

"Já é remansosa a jurisprudência dessa Suprema Corte no sentido de competir à Justiça estadual ○ julgamento das ações de acidente do trabalho.

Assim, temos proceder o conflito, devendo a competência caber à Justiça estadual da Guanabara".

\section{Voto}

O SR. MINISTRO AMARAL SANTOS (Relator) - Nos termos do parecer da douta Procuradoria-Geral da República conheço do conflito e o julgo procedente, para declarar competente o Trlbunal de Alçada do Estado da Guanabara.

\section{Voto}

O SR. MINISTRO THOMPSON FLORES - Quero, desde já, adiantar que estou de acordo com o eminente Relator, julgando procedente o conflito e competente o Tribunal de Alçada para apreciar, em segunda instância, as ações de acidente do trabalho, ainda que acionada seja autarquia federal ou a própria União.

Tenho como ainda vivos os enunciados nas súmulas nọs 235 e 501 , aquele firmado à sombra da Constituição de 1946; o último, de 1967, declarada a inconstitucionalidade do Art. 16, da Lei n? 5.316, de 1967, hoje 
com vigência suspensa, através de recente Resolução do Senado Federal (no 1, de 14-4-1970).

Certo, com o advento da Emenda Constitucional n: 1/1969, voltou a matéria de competência para ações de acidente a ser discutida.

Recebi trabalho escrito a respeito, de advogado de Brasília: cuidando do assunto, inclina-se pela competência da Justiça Federal. Seu autor, FERNANDO ABRANCHES, engenhosamente cotejando quesitos vários da Carta vigente, chega àquela conclusão:

Data venia, porém, tenho que os preceitos invocados não autorizam aquela afirmação.

Com efeito, dispõe o Art. $142, \S 2$, da Constituição em vigor.

"Os litigios relativos a acidentes do trabalho são da competência da justiça ordinária dos Estados, do Distrito Federal ou dos Territórios".

Suas expressões não permitem as dúvidas que originaram o Estatuto anterior. Precisas e claras, tornaram exato que em tema de acidente do trabalho a matéria, em lugar de ser resolvida pela Justiça do Trabalho, merecia solução pela Justiça ordinária dos Estados, do Distrito Federal e dos Territórios.

Invocam-se, em desfavor os arts. 125 , $\S 3$ ? e 110 , do Diploma em comentário.

O último cuida, é certo, de matéria trabalhista, mas não menos exato que estranha ao acidente do trabalho.

O primeiro, de disposição genérica, alusivo às causas, indistintamente consideradas, em que seja parte a Previ- dência Social, e cujo objeto seria de natureza pecuniária. E vasto é o rol nela compreendido.

Mas neles não se compreende os de acidente, porque excepcionou a própria Constituição, através do Art. 142 , $\S 2$ ?, refletindo-se ele sobre as demais regras, delas liberto pelo cunho da própria exceção.

Todas essas razões conspiram no propósito de tornar real a execução dos litígios sobre acidentes do trabaIho, aparelhadas como estão as Justiças dos Estados, de resto, com ambas instâncias, mas próximas dos interessados.

É o meu voto.

\section{Voto}

O SR. MINISTRO ELOY DA ROCHA - Sr. Presidente, quero aduzir breve consideração, sem voltar à discussão desenvolvida no CJ 3.893 , de 18-10-1967 (RTJ 44/360.369), que deu lugar à orientação enunciada na Súmula 501, sobre competência em matéria de acidente do trabalho.

A regra do $\S 3^{\circ}$, do Art. 125 , da Constituição, com a redação da Emenda $n$ ? 1 , de 17-10-1969, não incide na hipótese prevista no $\S 2$. do art. 142: "Os litígios relativos a acidentes do trabalho são da competência da justiça ordinária dos Estados, do Distrito Federal ou dos Territórios". Sobre este dispositivo, que constituiu exceção, não prevalece aquela regra.

O SR. MINISTRO AMARAL SANTOS - Não analisei o problema, porque esta questão já tem sido suscitada, aqui, muitas vezes. 
O SR. MINISTRO ELOY DA ROCHA

- Está sendo renovada a questão, em face do Art. $125 \S 3$ ? da Emenda $n$ ? 1. É conveniente que se reafirme a orientação do Supremo Tribunal. 0 § 3 ? do Art. 125 refere-se aos benefícios da previdência social, salvo os resultantes de acidente do trabalho. Deve a norma ser conciliada com o $\S 2$. do Art. 142 , que, de outra forma, não teria maior significação, mormente no sistema da L. 5.316, de 14-9-1967, que regulou a integração do seguro de acidentes do trabalho na previdência social.

Não fosse a predominância, da exceção, encontrar-se-ia razão para a competência desse Tribunal, igualmente, na vigência dos Arts. 119, I, 117 , II da Constituição de 1967. Orientou-se, contudo, a jurisprudência do Supremo Tribunal no sentido do princípio consagrado nas Súmulas 235 e 501.

De acordo com o eminente Relator, julgo procedente 0 conflito e competente o Tribunal de Alçada do Estado da Guanabara.

\section{Extrato da Ata}

CJ 5.345 - GB - Rel., Min. AMARAL SANTOS. Suste. Tribunal Federal de Recursos. Susdo. Tribunal de Alçada da Guanabara.

Decisão: Julgou-se competente o Tribunal de Alçada da Guanabara, unânimemente. Plenário, 14-5-70.

Presidência do Sr. Min. Oswaldo Trigueiro. Presentes à sessão os Srs. Mins. LUIZ GALLOTTI, ADALÍCIO NOGUEIRA, ALIOMAR BALEEIRO, ELOY DA ROCHA, DJACI FALCAO, ADAUTO CARDOSO, AMARAL SANTOS = THOMPSON FLORES.
Ausente, justificadamente, o Sr. Min. BARROS MONTEIRO

DR. ÁLVARO FERREIRA DOS SANTOS, Vice-Diretor-Geral" (certidão em poder do autor).

4. Os votos dos Srs. Ministros Thompson Flores e Eloy da Rocha são os que merecem discussão porque, o do Relator, ilustre Ministro Amaral Santos, não enfrentou, como se viu, a tese ventilada, e são acordes em afirmar que as SÚMULAS nos 235 e 501 foram inspiradas nas Constituições de 1946 e 1967.

Sem desconhecer que o Egrégio Tribunal Federal é o máximo intérprete autorizado das leis e, sobretudo, da Constituição, ousa-se em opinião indoula e desautorizzda, demonstrar que os ilustres Senhores Ministros, bem como os que os acompanharam, não destruiram, em seus lúcidos votos, a competência que se defendeu.

- Sr. Ministro Thompsom Flores, honrando o autor destas desataviadas considerações, citou-o em seu voto, mas, concluiu ser incorreta sua tese.

5. Entretanto, data venia, a conclusão do voto importa em negar o novo conceito de seguro social que a Carta Política de 1969, no inciso III, de seu art. 165, inseriu o seguro contra acidentes do trabalho, ao mesmo tompo em que considerou letra morta - que na disposição constitucional ficou expresso.

De outro lado, quando o autor destas reflexões citou o art. $110 \circ$ fez apenas para reforçar a argumentaçăo.

"A vigente Constituição desejou que qualquer litígio sobre tema de Direito do Trabalho, e que não ficasse afeto à 
justiça especial, fosse julgado pelos juízes federais, seja porque a União tem interesse direto na sua solução, seja porque ela ou a autarquia previdenciária são partes na formação do seguro social e no deferimento dos direitos dele conseqüentes. Quando assim não o quis deixou expresso, como acontece no caso dos litígios decorrentes das relações de trabalho dos servidores da União, com as autarquias e as empresas públicas federais, em que facultou à lei ordinária criar 0 contencioso administrativo, atribuindothe competência para o julgamento desses feitos, os quais, enquanto não acontecer, serão julgados pelos juizes federais, como preceituam os artigos 110 e $111 \ldots$ (5) $^{5}$

Criado este contencioso, atribuindoIhe a lei a competência para 0 julgamento de todos litígios a que se refere o art. 110, esvaziada ficará a competência dos juizes federais, bem como a do Tribunal Federal de Recurso, os quais não mais julgarão esses feitos.

Restar-lhes-á julgar, das causas sujeitas à Justiça do Trabalho, apenas as relativas aos acidentes do trabalho pela competência conferida no $\S 2$ ? do art. 142 da Constituição, e, ainda previstas no seu art. 125 .

15. E preciso deixar limpida, ainda, a correta interpretação do $\S 2^{\circ}$ do art. 142 da Constituição atual, a evidenciar que a justiça ali cogitada não é a dos juizes estaduais, ou locais do Distrito Federal ou dos Territórios.

Justiça ordinária dos Estados, do Distrito Federal ou dos Territórios é, segundo o que quer exprimir a nova Constituição, a dos juizes que exercem a judicatura naquelas unidades da Federação e dos Territórios, como os federais, no conteúdo novo do $\S$ 2 ? do art. 142, diverso do conteúdo do antigo $\S 2$ ? do art. 123 da Constituição de 1946 e do $\S 2$ ? do Art. 134 da Carta Política de 1967.

Se a atual Constituição quisesse que os litígios relativos aos acidentes do trabalho não fossemi decididos pelos juízes federais, teria aludido, no $\S 2$ ? do art. "142, à justiça estadual, do Distrito Federal ou dos Territórios, como procedeu toda vez que a esses juizes se referiu. Como exemplo, é suficiente lembrar o $\S 3$ ? de seu art. 125 e o inciso VI de seu art. 112". (6)

6. Do mesmo modo, data venia, não contrariou o ilustre $\mathrm{Sr}$. Ministro Thompson Flores, com argumentação convincente e válida, o desacerto ao comentário que se fez ao $\S 3$ ? do art. 125.

"Ora, o seguro contra acidente do trabalho, hoje, seguro social, é, sem dúvida, benefício de natureza pecuniária. Os benefícios dele emanados são sempre uma prestação em dinheiro e o seu pagamento é feito pela autarquia previdenciária e em qualquer ação dessa natureza ela será parte." ( ${ }^{(7)}$

Demais disto, não clareou o espírito dos que procuram compreender a matéria, contraditando a interpretação que deu ao art. 125, inciso I, para explicar que ela seria inadmissivel.

7. E conveniente denotar que a vigente Constituição, porque quis que os juizes federais julgassem matérias sujeitas à Justiça do Trabalho, dentre

5 ABRANCHES, idem, pág. 15.

6 Idem, págs. 16 e 17.

7 Idem, pág. 13. 
as quais o seguro social, não lhes excepcionou a competência, como fizera a de 1967.

De fato, dispõem o seu art. 125 e inciso I:

"Art. 125. Aos juizes federais compete processar e julgar em primeira instância:

I. As causas em que a União, entidade autárquica ou empresa pública federal forem interessadas na condição de autoras, rés, assistentes ou oponentes, exceto as sujeitas à Justiça Eleitoral ou Militar."

$E$ incontroverso, portanto, que estes juizes julgarăo todas as causas em que a autarquia previdenciária, o INPS, for parte, como autora, ré, assistente, ou opoente, inclusive as sujeitas à Justiça do Trabalho e que não sejam de sua competência especifica, exceto as subordinadas à Justiça Eleitoral ou Militar.

Foi outra inovação da Constituição que se comenta possibilitar a estes juízes, como adiante se verá no exemplo do $\S 3$ ? do seu art. 125 , o julgamento das ações de acidente do trabalho e dos litígios decorrentes das relações de trabalho dos servidores com a União, com as autarquias e empresas públicas federais.

É conveniente mostrar, também, e para que não paire dúvida em espíritos desavisados, que acidente do trabalho é materia atinente ao Direito do Trabalho, não só porque ele é tratado na Constituição no Capítulo VIII Sessão VII (Dos Tribunais e Juizes do Trabalho), senão também e principalmente porque no seu art. 165 , inciso $\mathrm{VI}$, assegurou aos trabalhadores seguro contra tais eventos. 8
Esta interpretação foi, ainda, demonstrada com maior amplitude e não parece ter sido negada.

"18. O novo legislador quis alterar a competência dos juizes federais e assim procedeu porque o seguro contra acidente do trabalho passou a constituir-se em seguro social que é, hoje, privativo da autarquia previdenclária, com a direta interferência da União na participação tríplice de contribuiçōes.

No exame das leis, e sobretudo da Carta Magna, procura-se conciliar as disposiçōes aparentemente contraditórias, com o objetivo de encontrar a correta interpretação, na constante preocupação de demonstrar que os dispositivos são harmônicos e interdependentes, de forma que um e outro se entrelace por liame indestrutivel.

Somente no caso de contradiçăo irreparável, que o bom-senso repudiasse, é que seria interpretado um artigo isoladamente.

Ora, não são inconciliáveis as normas constantes do art. 125 e seu $\S$ 3 ? e as do $\S 2$ ' do art. 142". ( $(9)$

$E$, quando o eminente Ministro afirma que

"todas estas razőes conspiram no propósito de tornar real a execução dos litígios sobre acidentes do trabatho, aparelhadas como estăo as Justiças dos Estados, de resto, com ambas as instâncias, mais próximas dos interessados"

não se recordou, por certo $e$ data venia, com que se delxou patenteado.

8 Idem, pág. 11.

9 Idem, pág. 21. 
"Quando o legislador, no inciso XVI do art. 165 , instituiu o seguro contra acidentes do trabalho em seguro social, porque a lei o estatizara, e o entregara privativamente ao INPS, resolveu modificar substancialmente a política social até então vigorante.

Seria uma iniqüidade, que o legislador não quis praticar, gesto mais do que elogiável, fossem o acidentado e seus beneficiários ficar privados de postular os seus direitos. Os seus minguados salários não lhes permitiriam deslocar-se de seu domicílio para intentar a ação que lhes coubesse.

O legislador, com prudente sabedoria e porque seguro social é direito constitucional em benefício do trabaIhador, no $\S 3.0$ do art. 125 , entregou aos juizes estaduais, dentre os quais os do Distrito Federal e os dos Territórios, sempre que a comarca não seja sede do juízo federal, a competência para a solução das causas dele conseqüentes.

É a exceção à regra do seguro social, que anteriormente não era seguro contra acidentes do trabalho, e que hoje o é, no novo sistema da política social que o legislador instituiu e porque entendeu de instituir.

Objetivando uniformizar a jurisprudência de tais litígios, ao mesmo tempo em que denota o seu desejo de firmar a competência da justiça federal, comum ou ordinária, determinou, em imperativo categórico, na mesma norma constitucional, que os recursos serão endereçados ao Tribunal Federal de Recursos". (10)

7. Quanto ao voto do eminente Ministro Eloy da Rocha, com o maior respeito e sem que se possa de leve notar qualquer irreverência, tudo 0 que foi dito ao mesmo se aplica, podendo acrescentar-se, contudo, que não se discute que a Lei 5.316 , de 14-9-1967 regulou a integração do seguro de acidentes do trabalho na previdência social, mas, que a vigente Carta Política, como se disse, não só o transformou em seguro social, como - estalizou de modo que lei alguma poderá retirá-lo desse conceito, salvo emenda Constitucional.

8. Mas, como se inseriu na SúMULA 501, a Constituição Federal, art. $142 \S 2$, e ambos os votos à mesma se reportam, será interessante apreciála, para os fins a que se destina este trabalho, destacando-se, de logo, que nenhum julgamento ainda fora proferído sob a sua vigência!

"SÚMULA 501 (Quinhentos o um)

Compete à Justiça ordinária estadual - processo e julgamento, em ambas as instâncias, das causas de acidente do trabalho, ainda que promovidas contra a União, suas autarquias, empresas públicas ou sociedades de economia mista".

\section{REFERENCIA}

C.F. 1967 , art. 134 § 2 ?

Lei $n$ ? 5.316, de 14-9-67 (D.0 de 18-9-67)

C.F. 1969 , art. $142 \S 2$ ?

Cj 3.893 , de 18-10-67, Pleno R.T.J. $44 / 360$

Cj 4.760 , de 27-2-69, Pleno Em. 758; D.J. 28-3-69

Cj 4.882 , de 5-3-69, Pleno Em. 762/1; D.J. 5-5-69(11)

10 Idem, págs. 21 e 22.

11 Ob. cit. Vol. 26, pág. 33. 
Cj 4.925 , de 27-2-69, Pleno Em. 759/1; D.J. 11-4-69"

O Conflito de Jurisdição n? 8.893, do Tribunal Pleno, primeira referência da Súmula, de que foi Relator o eminente Ministro Aliomar Baleeiro, hoje, Presidente do Supremo Tribunal Federal, cuida da espécie de que se discute, em face da Lei 5.316 de 14 de novembro de 1967, decidindo pela competência do Tribunal de Justiça do Estado da Guanabara, ao mesmo tempo em que declara a inconstitucionalidade do Art. 16, $\S \S 2$ e 3 ? dessa lei.

Entretanto, é confortador saber que o ilustre escoliaste e Relator comunga com uma das teses defendidas no estudo, de que este trabalho é complemento, o que, sem dúvida, indica estava o seu autor sob o agasalho de indiscutível autoridade.

"SR. MINISTRO ALIOMAR BALEEIRO (Relator) - O caso abre oportunidade para o primeiro pronunciamento do Supremo Tribunal Federal sobre a interpretação do $\S 2$ \% do Art. 134 da Constituiçăo de 1967, que estatui:

"Os dissídios relativos a acidentes do trabalho são da competência da Justiça Ordinária".

"Justiça Ordinária", nesse dispositivo, está empregado por oposição à Justiça Especial do Trabalho ou significa especificamente a Justiça dos Estados-membros? Justiça ordinária nas causas de acidentes intentadas contra a União, é a Federal?

Nisto, resume-se a questão a ser decidida no julgamento desse caso.

Considerando-se apenas o texto, tal como está redigido, sem contrastá-lo com o Direito anterior, os documentos legislativos pertinentes à elaboração do texto de 1967, a legislação ordinária suscitada por esse $\S 2$ ? do Art. 134 , as consideraçōes teleológicas ou pragmáticas, e outros elementos interpretativos, parece-me que "Justiça Ordinária" foi escrita ali apenas para exclusão de Justiça do Trabalho, e, então, será a Estadual ou a Federal, conforme a competência ratione personae.

Deve ser considerada então como "ordinária" nas causas em que for interessada a União, por si ou suas instrumentalidades de serviço público, a Justiça Federal. Nesse sentido, pronunciou-se a douta Procuradoria-Geral da República.

Não é só. Assim também entenderam o Congresso e o Poder Executivo, igualmente intérpretes autorizados da Constituição e que, na lição dos Hermeneutas, devem ser presumidos mais rigorosamente na prevenção da inconstitucionalidade do que o próprio Supremo Tribunal Federal, dado que a este, na dúvida, é aconselhável manifestar-se pela constitucionalidade reconhecida pelos outros dois Poderes nacionais.

Ora, a recente Lei $n$ ? 5.316 , de 14-9-67, que regula o monopólio do seguro de acidentes do trabalho pela Previdência Social dispõe que:

"Art. 16. Os juizes federais são competentes para julgar os dissidios decorrentes da aplicação desta lei.

$\S 1$ ? Quando não houver juiz federal no foro do acidente nem no da residência do acidentado, será competente a Justiça ordinária local. 
$\S 2$ \% 0 disposto neste artigo não conclui a utilização da via recursal da previdência social."

De certo, não é primorosa a técnica legislativa nem literária dessa norma. Mas, de qualquer modo, ela mostra a adesão do legislador à inteligência de que "Justiça Ordinária", por oposição à Justiça do Trabalho, pode ser a Estadual ou a Federal, conforme a competência ratione personae.

Há, ainda, outro argumento em abono dessa diretriz: o Ato Institucional $\mathrm{n}$ : 2, modificando a redação do Art. 105, § 3 ? , da Constituição de 1946, e o Art. 10 da Lei 5.010 , de 1966, que regulou a Justiça Federal, excetuavam expressamente do conhecimento desta as causas de falência e as de acidentes no trabalho. Ora, a Constituição, no Art. $134, \S 22^{\circ}$, restabeleceu a primitiva redação, que se refere à "Justiça Ordinária" e não conservou a execução expressa do Ato Institucional n? 2 e da Lei $5.010 / 66 " .12$

Quem perdeu tempo em ler o que se escreveu no estudo, deve ter tido ocasião de verificar que os princípios são os mesmos, apenas relacionados com a Constituição de 1969!

9. As conseqüências do Venerando Acórdão, no sentido de orientar a sua jurisprudência no que ficou consagrado nas SUMULAS 235 e 501 , vigente a Constituição de 1969 , são as mais imprevisíveis, e o brado de alerta, contido nos estudos que deram origem às presentes considerações, confirmou-se, deixando perplexos os juristas.

Mantida a competência que as Súmulas enunciam, o Supremo Tribunal Federal, data venia, paradoxalmente, malferiu, como será demonstrado, o sistema federativo que a Carta Politica atual consagra $e$, não havendo um Tribunal que uniformize a jurisprudência das ações de que se trata, cada Estado e o Distrito Federal decidirão com desuniformidade, o que, por certo, constitui precedente jamais visto no Direito brasileiro.

Não reformulada a competência, como era de esperar-se, que as Súmulas enunciam, ocorreu fato, indiscutivelmente, inusitado e ao mesmo tempo incompreensivel. Enquanto os temas de seguro social, tratados pela Lel Orgânica de Previdência Social, são discutidos e decididos pela Justiça Ordinária Federal, isto é, pelos juizes federais, com recurso para o Tribunal Federal de Recursos, podendo, em algumas hipóteses, serem reexaminados pelo Supremo Tribunal Federal, como, aliás, ocorre com qualquer ação (dependendo é, indiscutivel, do que dispuser o seu Regimento Interno), com jurisprudência que se torna pacífica e remansosa, os de seguro social, regulados pela Lei 5.316, de 1967 (acidentes do trabalho), o são pela Justiça Ordinária local dos Estados e do Distrito Federal, isto é, pelos juízes de primeiro grau, com recurso para os Tribunais de Justiça respectivos, onde se exaure a instância, passando em julgado as suas decisões, uma vez que o Recurso Extraordinário, na forma do Art. 308 , inciso II, letra a, do Regimento Interno acima referido, só será permitido nos casos de ofensa à Constituição ou discrepância manifesta de sua jurisprudência, o que, de resto, raramente, ocorrerá.

12 BALEEIRO, Aliomar (Presidente do Supremo Tribunal Federal), ob. cit., Vol. 27, págs. 35 e 36 . 
Assim, estes Tribunais divergem entre si e entre as suas próprias Turmas, onde há votos vencidos, muitos dos quais favoráveis ao próprio segurado acidentado, que todos procuram ajudar, sem que haja remédio para a anomalia.

10. O propósito do Supremo Tribunal Federal fol sadio, ninguém a isso põe dúvida, objetivando favorecer ao segurado acidentado, de modo que as ações acidentárias tivessem curso mais rápido.

Mas, mantida a orientação jurisprudencial das mencionadas Súmulas, o Supremo Tribunal, data venia, e de certo modo, paradoxalmente, feriu o inciso XVII, letra a, do Art. $8^{\circ}$, da Carta Política de 1969 que dá competência à União para legislar sobre, dentre outros, o direito do trabalho, o que importa, em última análise, em arranhar o sistema federativo, como se falou, por ela imposto categoricamente, desde que abdicou de sua competência, e a exclui do Tribunal Federal de Recursos, que poderia ser 0 uniformizador da jurisprudência.

É que os Acórdãos dos Tribunais de Justiça dos Estados e do Distrito Federal, divergentes, como se teve ocasião de lembrar, com o seu trânsito em julgado, fazem lei entre as partes, criando, de certa maneira, direito diverso em cada unidade da Federação e cujo paradoxo ficou sem soluçẩo.

Não será despropositado, à vista disto, o argumento absurdo de que há 23 (vinte e três) Direito do Trabalho, sobre o tema questionado, nos 22 (vinte e dois) Estados da Federação e o do Distrito Federal, um diverso do outro.
Não será tal anomalia a quebra do sistema federativo?

11. O Instituto Nacional de Previdência Social, o único, por força da Carta Política vigente a operar sobre o seguro social ficou e está atônito e sem meios para corrigir a anômala situação, vendo-se prejudicado, em unidades da Federação, com julgados, indisfarçavelmente ofensivos à Lei de Infortunistica.

o desfalque irreversível de que tem sido vítima, no seu patrimônio, não encontrou ressonância e não sabe até quando poderá suportá-lo?

12. De outro lado, alguns Tribunais de Justiça, ao invés de facilitarem a uniformização de sua própria jurisprudência, a dificultam, inadmitindo, por exemplo, os embargos de nulidade e infringentes do julgado, previsto no Art. 833, do Código de Processo Civel, apenas porque o dispositivo fala em decisão proferida em grau de apelação, em ação rescisória e em mandado de segurança.

E, não permitem, também, a sustentação oral, nos Agravos de Petlção, sob o fundamento de que, no sistema do Código de Processo Civil, ela não é prevista, e, quando a lel a quer autorizar, o faz de modo expresso, como no mandado de segurança (art. 12, da lei 1.533 , de 1951 , com as alterações subsequentes).

Restaria, então, ao INPS, como salvação extrema, de quem se sente afogado e já sem fôlego, o recurso de Revista, que, além de dificil admissão, como é corriqueiro, viria sanar em parte o problema e perante o Tribunal onde fosse interposto, mas, as decisões poderiam, não ser aceitas 
pelos demais Tribunais de Justiça dos Estados.

13. Aos Tribunais de Justiça, já que o Supremo Tribunal Federal, ao que tudo indica, não reverá a sua orientação, caberia, procurando sanar um pouco a constrangedora situação, admitir embargos, a que se fez referência, como a sustentação oral, nos Agravos de Petição uma vez que este recurso equivale, na tormentosa questão, ao de apelação, com a diferença de que, do Acórdão, não caberá $\circ$ Recurso Extraordinário, a não ser nos casos já apontados.

A construção, a ser adotada por estes Tribunais nada teria de desprimoroso e, ao revés, só poderia merecer aplausos, como não seria esdrúxula, uma vez que o Agravo de Petição, previsto no Art. 846 , do Código de Processo Civil, é admitido nas decisões que impliquem na terminação do processo principal sem the resolverem o mérito, sendo, que, provido, as partes terão o ensejo de interpor a apelação.

$E$, não seria despiciendo lembrar para este propósito que o legislador, quando da Lei 5.316, de 1967, e o constituinte, da Carta Política de 1969, tinham conhecimento de que das decisões de que se examina cabia o Recurso Extraordinário, que, somente depois, e não é canșativo rememorar, passou a ser inadmitido, salvo as exceçöes consignadas.

14. Tão grave e séria é a questão que o Tribunal de Justiça do Distrito Federal, alertado pelas dificuldades por que estava passando o INPS, em face da divergência de julgados, não só entre as suas turmas e entre ele e os outros Tribunais dos Estados, que uma de suas Turmas, melhor estudando as teses do instituto, que é pouco conhecido e mal compreendido, está reformulando sua jurisprudência para ajustá-la à correta interpretação da lel e do direito, o que, sem dúvida, é meritório.

15. A verdade é que a matéria é apaixonante e a maioria dos magistrados, por força do hábito, ainda não sentiram que o instituto não é mais o do conceito antigo, na vigência de leis anteriores, e que, com a Lei 5.316, de 1967 , e, notadamente, com a Constituição de 1969, como ficou exaustivamente explanado, o segurado acidentado é recebido e tratado, no INPS, do mesmo modo que o são os segurados, cujos direitos são regidos pela Lei Orgânica de Previdência Social.

Com o monopólio do seguro social, que a Carta Magna em tão feliz oportunidade estabeleceu, não há mais a comercialização do seguro contra acidentes do trabalho na época em que o contrato era celebrado com empresas particulares.

$\mathrm{Na}$ época atual, como, aliás, é tendência em outros paises, conforme recomendação da Organização Internacional do Trabalho (OIT), ele é, entre nós, seguro social, não tendo. 0 Estado, através de sua maior autarquia federal, interesse em prejudicar o segurado acidentado, e, pelo contrário, o seu desejo é vê-lo em alta, com saúde, recuperado para o trabalho e, mais, reabilitado profissionalmente, para evitar que se torne um ocioso, descambando até mesmo para a criminalidade. 
E, para não alongar este trabalho, e apenas para deixar mais claro que este conceito, na atualidade, é outro, será suficiente levar em conta que a Lei de Infortunística substituiu o prêmio, que era exigido pelo Decreto-lei n? 7.036, de 1944, inaplicável nos casos da Lei vigente, por uma contribuição de natureza previdencial, norma reproduzida em seu Regulamento.

16. Um dos argumentos alinhados no voto do ilustre Ministro Aliomar Baleeiro, no Conflito de Jurisdição a que se aludiu, no que tange à Emenda do então Senador Gilberto Mari-. nho, e apoiado pelo Senador Eurico Rezende, de que "o projeto do Governo não continha o dispositivo excludente (o Art. $134, \S 2$ - - referindo-se à Constituição de 1967), com milhares de ações em vários Estados, não mais poderia ser aceito, se houvesse um Tribunal a uniformizar a jurisprudência do seguro social no seu novo conceito, sendo certo que, em razão disto, o fato não mais poderia ocorrer.

17. Mais uma vez aqui ficam as admoestações, chamando-se a atenção do Supremo Tribunal Federal, e com o maior respeito, para que, em tempo, corrija a anomalia, clamor que é feito pelo amor que 0 advogado que este subscreve devota ao PODER JUDICIARIO, esperando, é evidente, melhores luzes dos doutos e que, por certo, possam mostrar-lhe o desacerto de suas teses. 
